\title{
PENGARUH MEKANISME GCG DAN CSR TERHADAP KINERJA KEUANGAN YANG DIMEDIASI MANAJEMEN LABA
}

\author{
Renaldy Alviansyah dan I Gede Adiputra \\ Program Studi Manajemen Fakultas Ekonomi Universitas Tarumanagara, Jakarta \\ Email : renaldyalviansyah@gmail.com
}

\begin{abstract}
This study examines the impact of corporate governance mechanism and corporate social responsibility to financial performance. This study consists of four independent variables, one mediating variable, and three dependent variables, namely the proportion of independent board of commissioners, institutional ownership, audit committee, and corporate social responsibility as an independent variabel, earnings management as a mediating variable, and ROA, EPS, and Tobin;s $Q$ as the dependent variable. The research method used is descriptive method with a qualitative approach. The sample in this study are 19 manufacturing company which listed on the Indonesia Stock Exchange from 2017 until 2019 who selected through purposive sampling method. The result of this study are the proportion of independent board of commissioners and institutional ownership not significant negative effect on earnings management, the audit committee has a significant positive effect on earnings management, corporate social responsibility has no significant positive effect on earnings management, corporate governance mechanisms do not have a significant negative effect on ROA, the proportion of independent commissioners and institutional ownership did not have a significant negative effect on EPS, the audit committee did not have a significant positive effect on EPS, corporate governance mechanisms did not have a significant positive effect on Tobin's $Q$, corporate social responsibility did not have a significant negative effect on financial performance, earnings management does not have a significant negative effect on $R O A$, earnings management has a significant negative effect on Tobin's $Q$, earnings management does not have a significant positive effect mut on EPS, governance mechanisms per business have a positive effect on ROA and EPS mediated by earnings management, corporate governance mechanisms negatively affect Tobin's $Q$ mediated by earnings management, and corporate social responsibility has a positive effect on mediated financial performance by earnings management.
\end{abstract}

Keywords: corporate governance mechanism, corporate social responsibility, earnings management, financial performance.

Abstrak: Penelitian ini bertujuan untuk menganalisis pengaruh Mekanisme Tata Kelola Perusahaan dan Tanggung Jawab Sosial Perusahaan terhadap Kinerja Perusahaan. Penelitian ini terdiri dari empat variabel independen, satu variabel mediasi, dan tiga variabel dependen, yaitu proporsi dewan komisaris independen, kepemilikan institusional, komite audit, dan tanggung jawab sosial perusahaan sebagai variabel independen, manajemen laba sebagai variabel mediasi, dan ROA, EPS, dan Tobin's Q sebagai variabel dependen. Metode riset yang digunakan adalah metode deskriptif dengan pendekatan kualitatif. Sampel dari penelitian ini adalah 19 perusahaan manufaktur yang terdaftar di Bursa Efek Indonesia dari 2017 sampai 2019 yang ditentukan menggunakan metode purposive sampling. Hasil dari penelitian ini adalah proporsi dewan komisaris independen dan kepemilikan institusional berpengaruh negatif tidak signifikan terhadap manajemen laba, komite audit berpengaruh positif signifikan terhadap manajemen laba, tanggung jawab sosial perusahaan berpengaruh positif tidak 
signifikan terhadap manajemen laba, Mekanisme tata kelola perusahaan berpengaruh negatif tidak signifikan terhadap ROA, proporsi dewan komisaris independen dan kepemilikan institusional berpengaruh negatif tidak signifikan terhadap EPS, komite audit berpengaruh positif tidak signifikan terhadap EPS, mekanisme tata kelola perusahaan berpengaruh positif tidak signifikan terhadap Tobin's Q, tanggung jawab sosial perusahaan berpengaruh negatif tidak signifikan terhadap kinerja keuangan, manajemen laba berpengaruh negatif tidak signifikan terhadap ROA, manajemen laba berpengaruh negatif signifikan terhadap Tobin's Q, manajemen laba berpengaruh positif tidak signifikan terhadap EPS, mekanisme tata kelola perusahaan berpengaruh positif terhadap ROA dan EPS dimediasi oleh manajemen laba, mekanisme tata kelola perusahaan berpengaruh negatif terhadap Tobin's Q dimediasi oleh manajemen laba, dan tanggung jawab sosial perusahaan berpengaruh positif terhadap kinerja keuangan dimediasi oleh manajemen laba.

Kata kunci: mekanisme tata kelola perusahaan, tanggung jawab sosial perusahaan, manajemen laba, kinerja keuangan.

\section{LATAR BELAKANG}

Laporan keuangan perusahaan adalah salah satu indikator yang digunakan untuk menilai keberhasilan perusahaan dan dapat digunakan sebagai bentuk pertanggungjawaban atas kinerja yang telah dilakukan oleh manajemen perusahaan. Dalam perusahaan manajemen berperan sebagai agen dimana tugasnya untuk mengatur serta mengelola sumber daya yang ada pada perusahaan yang tentunya mengetahui semua informasi yang ada dalam perusahaan dan tujuan perusahaan ke depannya. Karena mengetahui semua informasi yang ada dalam perusahaan adakalanya manajer memberikan laporan keuangan yang tidak sesuai dengan kondisi yang sebenarnya terjadi dalam perusahaan kepada para pemegang saham. Hal tersebut memungkinkan para manajer untuk melakukan manajemen laba agar perusahaan dapat dinilai mempunyai kinerja yang baik.

Maka dari itu dibutuhkan suatu kebijakan untuk mengatur pengelolaan perusahaan agar meminimalkan perbedaan kepentingan yang terjadi antara manajer dan pemegang saham. Upaya yang dapat digunakan untuk menangani konflik keagenan adalah mekanisme good corporate governance. Dengan menerapkan mekanisme good corporate governance diharapkan dapat memberi rasa yakin kepada pemegang saham untuk menginvestasikan dana yang mereka punya ke perusahaan.

Corporate social responsibility merupakan salah satu bentuk pelaksanaan dari good corporate governance, Tujuan dilakukannya corporate social responsibility adalah untuk meningkatkan citra perusahaan di mata masyarakat agar perusahaan mempunyai reputasi yang baik sehingga mempengaruhi kinerja keuangan perusahaan.

Karena kinerja keuangan dapat menggambarkan kondisi keuangan dari perusahaan maka peran dari kinerja keuangan ini sangat penting. Akibatnya ada perusahaan pada saat menerbitkan laporan keuangannya tidak sesuai dengan kondisi yang sebenarnya, seperti contoh kasus yang baru-baru ini terjadi kepada PT Garuda Indonesia Tbk. Sehingga dengan diterapkannya good corporate governance pada perusahaan secara konsisten diharapkan kinerja keuangan perusahaan dapat menjadi lebih baik dan menguraingi manajemen laba di perusahaan. 


\section{KAJIAN TEORI}

\section{Good Corporate Governance}

Menurut Tunggal (2013:149), Corporate governance adalah sistem dan struktur untuk mengelola perusahaan dengan tujuan meningkatkan nilai pemegang saham serta mengakomodasi berbagai pihak yang berkepentingan dengan perusahaan (stakeholders) seperti kreditor, supplier, asosiasi usaha, konsumen, pekerja, pemerintah dan masyarakat luas. Berdasarkan definisi diatas, dapat disimpulkan bahwa good corporate governance merupakan ketentuan yang harus dijalankan oleh perusahaan yang bertujuan untuk meningkatkan kesejahteraan para stakeholder serta menghindari aktivitas manajemen laba yang dilakukan oleh manajer.

\section{Corporate Social Responsibility}

Menurut Wibisono (2007:7), Corporate Social Responsibility (CSR) adalah suatu komitmen berkelanjutan oleh dunia usaha untuk bertindak etis dan memberikan kontribusi kepada pengembangan ekonomi dari komunitas setempat atau masyarakat luas, bersaman dengan peningkatan taraf hidup pekerja beserta keluarganya. Berdasarkan definisi diatas, maka dapat disimpulkan bahwa corporate social responsibility adalah bentuk komitmen perusahaan terhadap lingkungan sekitar perusahaan maupun masyarakat luas sebagai bentuk pertanggungjawaban perusahaan atas aktivitas yang telah dilakukan untuk meningkatkan kesejahteraan masyarakat.

\section{Financial Performance}

Menurut IAI (2007), Kinerja keuangan adalah kemampuan perusahaan dalam mengelola dan mengendalikan sumber daya yang dimiliki. Berdasarkan definisi diatas, maka dapat disimpulkan bahwa kinerja perusahaan adalah penilaian terhadap kondisi keuangan perusahaan yang menunjukkan kemampuan perusahaan dalam mengelola dan mengatur sumber daya yang dimiliki yang dilaporkan dalam bentuk laporan keuangan perusahaan dan digunakan sebagai tolak ukur manajemen atau manajer perushaan untuk meningkatkan kinerja perusahaan pada periode berikutnya.

\section{Earnings Management}

Menurut Meutia (2004), Manajemen laba (Earnings management) adalah usaha pihak manajer yang disengaja untuk memanipulasi laporan keuangan dalam batasan yang dibolehkan oleh prinsip akuntansi dengan tujuan memberikan informasi yang menyesatkan para pengguna laporan keuangan untuk kepentingan pihak manajer. Berdasarkan definisi diatas, maka dapat disimpulkan bahwa manajemen laba adalah usaha yang dilakukan oleh manajer dalam menetapkan laba perusahaan yang bertujuan untuk mendapatkan keuntungan pribadi.

\section{Kaitan antara Mekanisme Good Corporate Governance dengan Financial Performance}

Menurut Kurniati (2019), Agency cost namely the sum of the costs of supervision by the owner through the board of commissioners, institutional ownership, and public ownership as a tool, mechanism and the structure used to check self-serving managerial behavior, limits opportunistic behavior of managers, improves the quality of company information and arranges relationships between all parties so that their interests can be accommodated in a balanced manner. Dengan demikian mekanisme good corporate governance dapat mempengaruhi financial performance dimana jika penerapannya dilaksanakan dengan benar 
akan memberikan keputusan yang objektif dari manajer, membuat perusahaan semakin efektif, dan meningkatkan kinerja perusahaan.

\section{Kaitan antara Corporate Social Responsibility dengan Financial Performance}

Corporate Social Responsibility dapat mempengaruhi financial performance dikarenakan CSR dapat meningkatkan tingkat kepercayaan masyarakat terhadap perusahaan, meningkatkan reputasi perusahaan, dan meninggkatkan loyalitas konsumen terhadap perusahaan yang nantinya akan mempengaruhi kinerja perusaahn. Selain meningkatkan hubungan baik antara perusahaan dengan konsumen kegiatan CSR juga berpartisipasi membangun lingkungan sekitar perusahaan sehingga membangun hubungan baik dengan masyarakat dan juga pemerintah. Beberapa penelitian yang membuktikan bahwa CSR memiliki pengaruh positif terhadap kinerja keuangan perusahaan dilakukan oleh Saleh et al. (2011), Palmer (2012), Ghelli (2013), dan Ahamed et al. (2014).

\section{Kaitan antara Mekanisme Good Corporate Governance dengan Earnings Management}

Menurut penelitian yang dilakukan oleh Lee et al, (2012), Uwuigbe et al, (2014) dan Kamran dan Shah (2014) membuktikan bahwa mekanisme good corporate governance memiliki pengaruh negatif terhadap earnings management. Sedangkan penelitian yang dilakukan oleh Hermiyetti dan Manikand Al-Yhuneibat et al, (2016) membuktikan bahwa mekanisme good corporate governance memiliki pengaruh yang tidak signifikan terhadap earnings management. Hal tersebut dikarenakan implementasi mekanisme good corporate governance yang dilakukan hanya berfungsi sebagai bentuk kepatuhan perusahaan terhadap hukum dan peraturan pemerintah, sehingga penerapan dari mekanisme good corporate governance menjadi tidak efektif dan tidak optimal dalam mengawasi kinerja manajemen.

\section{Kaitan antara Corporate Social Responsibility dengan Earnings Management}

Dalam penelitian yang dilakukan oleh Prior et al (2008), menemukan bahwa corporate social responsibility memiliki hubungan positif terhadap earnings management. Sedangkan penelitian yang dilakukan oleh Kumala dan Siregar (2020) dan penelitian yang dilakukan oleh Liu dan Lee (2019) memberikan hasil yang sama dimana CSR berpengaruh negatif terhadap manajemen laba dan efektif untuk mengurangi kegiatan manajemen laba.

\section{Kaitan antara Earnings Management dengan Financial Performance}

Earnings management dapat menurunkan kualitas informasi laporan keuangan yang disajikan terkait dengan laba perusahaan.. Menurut penelitian yang dilakukan oleh Akram et al. (2015), menyimpulkan bahwa earnings management actions can reduce financial performance. Penelitian yang dilakukan oleh Mahdavi-Ardekanietal, (2012) dan juga penelitian yang dilakukan Mayang Mahrani dan Noorlailie Soewarno (2018), mengidentifikasi bahwa adanya hubungan negatif antara earnings management dengan financial performance. Kumari dan Pattanayak (2017), dalam penelitiannya membuktikan bahwa adanya keterkaitan yang signifikan antara manajemen laba dengan kinerja perusahaan.

Kaitan antara Mekanisme Good Corporate Governance dengan Financial Performance melalui Earnings Management 
Secara teori, pelaksanaan good corporate governance dapat meningkatkan kinerja keuangan perusahaan, mengurangi risiko yang mungkin terjadi dengan keputusan yang mendukung tata kelola perusaaan. Keputusan dari dewan komisaris independent untuk memilih auditor dengan reputasi yang baik agar dapat memberikan pengawasan yang besar kepada manajemen agar tidak melakukan earnings management dalam laporan keuangan. Pengawasan yang dilakukan dapat meminimalkan kemungkinan tindak kecurangan yang dilakukan oleh manajer.. Menurut penelitian yang dilakukan oleh Ching et al. (2015) dan Setiawan (2015) memberikan bukti empiris bawa good corporate governance dapat mempengaruhi financial performance melalui earning management.

\section{Kaitan antara Corporate Social Responsibility dengan Financial Performance melalui Earnings Management}

Kegiatan CSR yang dilakukan oleh perusahaan dapat membatu perusahaan agar mendapatkan dukungan dari lingkungan masyarakat agar perusahaan dapat beroperasi dengan semestinya. Perusahaan yang sudah menerapkan CSR akan membuat pelaporan keuangan menjadi trasnparan sehingga membuat para manajer untuk mengurangi praktik earnings management. Dalam penelitian yang dilakukan oleh Sial et al (2018), mengidentifikasi bahwa CSR memberikan efek negatif terhadap kinerja keuangan jika melalui manajemen laba. Sedangkan penelitian yang dilakukan oleh Rosa Priskila Sitanggang dan Dwi Ratmono (2019), mengidentifikasikan bahwa CSR terhadap kinerja keuangan perusahaan yang dimedisai oleh manajemen laba berpengaruh positif.

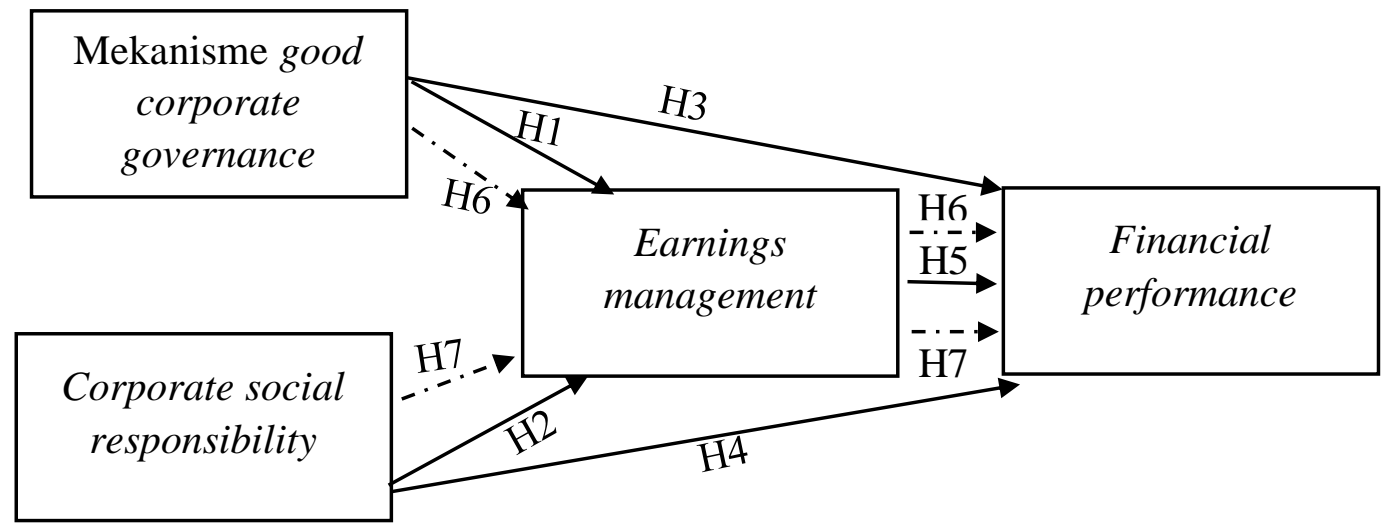

Gambar 1. Model Penelitian

\section{METODOLOGI}

Penelitian ini akan menggunakan metode deskirptif. Dimana variable yang digunakan dalam penelitian ini adalah Mekanisme Good Corporate Governance, Corporate Social Responsibility, Financial Performance dan Earnings Management. Analisis penelitian yang digunakan dalam penelitian ini menggunakan pendekatan kuantitatif, dengan tujuan untuk menguji hipotesis yang telah ditentukan. Sample didapatkan dengan menggunakan metode purposive sampling. Pada penelitian ini pengambilan sample secara tidak acak yang didapatkan dari Bursa Efek Indonesia (BEI) pada periode 2017 - 2019. 


\section{HASIL ANALISIS DATA}

\section{Hasil Uji Multikolinearitas}

Tabel 1. Hasil Uji Multikolinearitas

\begin{tabular}{crrrc} 
& KA & KI & PDKI & CSR \\
\hline \hline KA & 1.000000 & 0.134744 & -0.189870 & 0.085120 \\
KI & 0.134744 & 1.000000 & -0.420337 & 0.350127 \\
PDKI & -0.189870 & -0.420337 & 1.000000 & 0.043725 \\
CSR & 0.085120 & 0.350127 & 0.043725 & 1.000000
\end{tabular}

Table diatas menunjukan hasil dari uji multikolinearitas dimana nilai dari korelasi setiap variabel independen kurang dari 0,8. Kesimpulan dari uji multikolinearitas ini adalah setiap variabel independent dalam penelitian ini tidak memiliki hubungan linear dan tidak mengalami multikolinearitas dalam model regresi.

\section{Hasil Uji Chow}

Tabel 2. Hasil Uji Chow

\begin{tabular}{lrrr}
\hline \hline Effects Test & Statistic & d.f. & Prob. \\
\hline \hline Cross-section F & 45.125916 & $(18,33)$ & 0.0000 \\
Cross-section Chi-square & 184.859230 & 18 & 0.0000 \\
\hline \hline
\end{tabular}

Dari hasil uji Chow diatas, menunjukkan bahwa nilai probabilitas cross-section $\mathrm{F}$ sebesar 0,0000 dan nilai probabilitas cross-section chi-square sebesar 0,0000 yang berarti bahwa nilai probabilitas cross-section $\mathrm{F}<0.05$. Maka kesimpulan dari uji chow adalah Ho ditolak, jadi fixed effect model adalah model regresi yang dipilih dari uji Chow. Kemudian dilakukan uji Hausman untuk menentukan model random effect model atau fixed effect model.

\section{Hasil Uji Hausman}

Tabel 3. Hasil Uji Hausman

\begin{tabular}{llrl}
\hline \hline Test Summary & $\begin{array}{l}\text { Chi-Sq. } \\
\text { Statistic }\end{array}$ & Chi-Sq. d.f. & Prob. \\
\hline \hline Cross-section random & 10.627677 & 5 & 0.0593 \\
\hline \hline
\end{tabular}

Dari hasil uji Hausman diatas, menunjukkan bahwa nilai probabilitas cross-section random sebesar 0,0593 yang berarti bahwa nilai probabilitas cross-section random $>0.05$. Maka kesimpulan dari uji Hausman adalah Ho tidak ditolak, jadi random effect model adalah model regresi yang dipilih dari uji Hausman. Kemudian dilakukan uji Langrange Multiplier untuk menentukan model common effect model atau random effect model. 


\section{Hasil Uji Langrange Multiplier}

Tabel 4. Hasil Uji Langrange Multipler

\begin{tabular}{lccc}
\hline \hline $\begin{array}{l}\text { Null (no rand. } \\
\text { effect) } \\
\text { Alternative }\end{array}$ & $\begin{array}{c}\text { Cross-section } \\
\text { One-sided }\end{array}$ & $\begin{array}{c}\text { Period } \\
\text { One-sided }\end{array}$ & Both \\
\hline \hline Breusch-Pagan & $\begin{array}{l}35.20813 \\
(0.0000)\end{array}$ & $\begin{array}{l}1.458721 \\
(0.2271)\end{array}$ & $\begin{array}{l}36.66685 \\
(0.0000)\end{array}$
\end{tabular}

Dari hasil uji Langrange Multiplier diatas, menunjukkan bahwa nilai probabilitas crosssection Breusch-Pagan sebesar 0,0000 yang berarti bahwa nilai probabilitas cross-section Breusch-Pagan < 0.05. Maka kesimpulan dari uji Breusch-Pagan adalah Ho ditolak, jadi random effect model adalah model regresi yang dipilih dari uji Langrange Multiplier.

\section{Hasil Uji t}

Tabel 5. Hasil Uji t Tahap 1

\begin{tabular}{crrrr}
\hline \hline Variable & Coefficient & Std. Error & t-Statistic & Prob. \\
\hline \hline C & $-6.71 \mathrm{E}+12$ & $1.59 \mathrm{E}+12$ & -4.228590 & 0.0001 \\
PDKI & $-2.46 \mathrm{E}+10$ & $1.37 \mathrm{E}+10$ & -1.792620 & 0.0789 \\
KI & $-8.24 \mathrm{E}+09$ & $4.62 \mathrm{E}+09$ & -1.784419 & 0.0802 \\
KA & $2.72 \mathrm{E}+12$ & $4.30 \mathrm{E}+11$ & 6.330479 & 0.0000 \\
CSR & $1.41 \mathrm{E}+09$ & $1.25 \mathrm{E}+10$ & 0.113237 & 0.9103 \\
\hline \hline
\end{tabular}

Dari tabel hasil uji t diatas menunjukkan bahwa nilai probabilitas mekanisme good corporate governance yang diproyeksikan dengan proporsi dewan komisaris independent dan kepemilikan institusional lebih besar dari tingkat signifikansi 0.05 yaitu masing-masing sebesar 0.0789 dan 0.0802 dapat disimpulkan jika Ho tidak ditolak yang berarti proporsi dewan komisaris independent dan kepemilikan institusional tidak berpengaruh signifikan terhadap manajemen laba pada perusahaan manufaktur yang tercatat di BEI periode 2017-2019. Sedangkan nilai probabilitas komite audit lebih kecil dari tingkat signifikansi 0.05 yaitu sebesar 0 dapat disimpulkan jika Ho ditolak yang berarti komite audit berpengaruh signifikan terhadap manajemen laba pada perusahaan manufaktur yang tercatat di BEI periode 2017-2019. Dari tabel hasil uji t diatas menunjukkan bahwa nilai probabilitas Corporate social responsibility lebih besar dari tingkat signifikansi 0.05 yaitu sebesar 0.9103 dapat disimpulkan jika Ho tidak ditolak yang berarti Corporate social responsibility tidak berpengaruh signifikan terhadap manajemen laba pada perusahaan manufaktur yang tercatat di BEI periode 2017-2019.

Tabel 6. Hasil Uji t Tahap 2

\begin{tabular}{crrrr}
\hline \hline Variable & Coefficient & Std. Error & t-Statistic & Prob. \\
\hline \hline C & 1.198255 & 3.623940 & 0.330650 & 0.7423 \\
PDKI & 0.009572 & 0.025650 & 0.373193 & 0.7106 \\
KI & 0.013677 & 0.009851 & 1.388408 & 0.1710 \\
KA & 0.076712 & 1.039543 & 0.073794 & 0.9415 \\
CSR & -0.041654 & 0.036732 & -1.133998 & 0.2621 \\
MANAJEMEN_LABA & $-3.85 \mathrm{E}-13$ & $1.91 \mathrm{E}-13$ & -2.015066 & 0.0492 \\
\hline \hline
\end{tabular}


Dari tabel diatas menunjukkan bahwa nilai probabilitas mekanisme good corporate governance yang diproyeksikan dengan proporsi dewan komisaris independent, kepemilikan institusional dan komite audit lebih besar dari tingkat signifikansi 0.05 yaitu masing-masing sebesar 0.7106, 0.1710,dan 0.9415 dapat disimpulkan jika Ho tidak ditolak yang berarti proporsi dewan komisaris independent, kepemilikan institusional, dan komite audit tidak berpengaruh signifikan terhadap tobin's Q pada perusahaan manufaktur yang tercatat di BEI periode 2017-2019. Dari tabel diatas menunjukkan bahwa nilai probabilitas corporate social responsibility lebih besar dari tingkat signifikansi 0.05 yaitu sebesar 0.2621 dapat disimpulkan jika Ho tidak ditolak yang berarti corporate social responsibility tidak berpengaruh signifikan terhadap tobin's Q pada perusahaan manufaktur yang tercatat di BEI periode 2017-2019. Dari tabel diatas menunjukkan bahwa nilai probabilitas earnings management lebih kecil dari tingkat signifikansi 0.05 yaitu sebesar 0.0492 dapat disimpulkan jika Ho ditolak yang berarti earnings management berpengaruh signifikan terhadap tobin's Q pada perusahaan manufaktur yang tercatat di BEI periode 2017-2019.

\section{Analisis Jalur}

Nilai yang digunakan untuk analisis jalur diperoleh dari tabel uji t. Pengaruh tidak langsung proporsi dewan komisaris independen sebesar $-24600000000 \mathrm{x}-0.000000000000385$ $=0.009471<0.009572$ yaitu nilai pengaruh langsung proporsi dewan komisaris independen maka disimpulkan variabel earnings management tidak dapat memediasi proporsi dewan komisaris independen terhadap Tobin's Q yang artinya proporsi dewan komisaris independen tidak berpengaruh positif terhadap Tobin's yang dimediasi oleh manajemen laba. Pengaruh tidak langsung kepemilikan institusi sebesar $-8240000000 \mathrm{x}-0.000000000000385=0.0031724$ $<0.013677$ yaitu nilai pengaruh langsung kepemilikan institusional maka disimpulkan variabel earnings management tidak dapat memediasi kepemilikan institusional terhadap Tobin's Q yang artinya kepemilikan institusional tidak berpengaruh positif terhadap Tobin's Q yang dimediasi oleh manajemen laba. Pengaruh tidak langsung komite audit sebesar $2720000000000 \times-0.000000000000385=-1.0472<0.076712$ yaitu nilai pengaruh langsung komite audit maka disimpulkan variabel earnings management tidak dapat memediasi komite audit terhadap Tobin's Q yang artinya komite audit tidak berpengaruh positif terhadap Tobin's Q yang dimediasi oleh manajemen laba. Pengaruh tidak langsung corporate social responsibility sebesar $1410000000 \times-0.000000000000385=-0.00054285>-0.041654$ yaitu nilai pengaruh langsung corporate social responsibility maka disimpulkan variabel earnings management dapat memediasi corporate social responsibility terhadap Tobin's Q yang corporate social responsibility tidak berpengaruh positif terhadap Tobin's Q yang dimediasi oleh manajemen laba.

\section{Hasil Uji Koefisien Determinasi $\left(\mathbf{R}^{\mathbf{2}}\right)$}

Tabel 7. Hasil Uji Koefisien Determinasi Tahap 1

\begin{tabular}{lclc}
\hline \hline Root MSE & $8.59 \mathrm{E}+11$ & R-squared & 0.430437 \\
Mean dependent var & 0.001206 & Adjusted R-squared & 0.386624 \\
S.D. dependent var & $1.15 \mathrm{E}+12$ & S.E. of regression & $9.00 \mathrm{E}+11$ \\
Sum squared resid & $4.21 \mathrm{E}+25$ & F-statistic & 9.824502 \\
Durbin-Watson stat & 2.406790 & Prob(F-statistic) & 0.000005 \\
\hline \hline
\end{tabular}

Dari tabel hasil koefisien determinasi tahap 1 di atas menunjukkan nilai adjusted $\mathrm{R}^{2}$ sebesar 0.386624 yang berarti pengaruh variabel mekanisme good corporate governance (proporsi dewan komisaris independen, kepemilikan institusional, komite audit) dan corporate 
social responsibility terhadap earnings management adalah sebesar $38.66 \%$ sedangkan sisanya sebesar $61.34 \%$ dapat dijelaskan oleh variabel lain yang berasal dari luar variabel independen penelitian ini.

Tabel 8. Hasil Uji Koefisien Determinasi Tahap 2

\begin{tabular}{llll}
\hline \hline Root MSE & 0.991620 & R-squared & 0.114405 \\
Mean dependent var & 0.653056 & Adjusted R-squared & 0.027582 \\
S.D. dependent var & 1.063093 & S.E. of regression & 1.048329 \\
Sum squared resid & 56.04873 & F-statistic & 1.317686 \\
Durbin-Watson stat & 1.061646 & Prob(F-statistic) & 0.271449 \\
\hline \hline
\end{tabular}

Dari tabel hasil koefisien determinasi di atas menunjukkan nilai adjusted $\mathrm{R}^{2}$ sebesar 0.027582 yang berarti pengaruh variabel mekanisme good corporate governance (proporsi dewan komisaris independen, kepemilikan institusional, komite audit), earnings managemen, dan corporate social responsibility terhadap Tobin's Q adalah sebesar $2.76 \%$ sedangkan sisanya sebesar 97.24\% dapat dijelaskan oleh variabel lain yang berasal dari luar variabel independen penelitian ini.

\section{PENUTUP}

Berdasarkan hasil penelitian yang ada, maka dapat disimpulkan sebagai berikut :

1) Proporsi dewan komisaris independen dan kepemilikan institusional berpengaruh negatif tidak signifikan terhadap earning management pada perusahaan manufaktur yang tercatat pada Bursa Efek Indonesia tahun 2017 - 2019. Tetapi komite audit berpengaruh positif signifikan terhadap earning management pada perusahaan manufaktur yang tercatat pada Bursan Efek Indonesia tahun 2017 - 2019.

2) Corporate social responsibility berpengaruh positif tidak signifikan terhadap earnings management pada perusahaan manufaktur yang tercatat pada Bursa Efek Indonesia tahun 2017 - 2019.

3) Mekanisme good corporate governance berpengaruh negatif tidak signifikan terhadap ROA pada perusahaan manufaktur yang tercatat pada Bursan Efek Indonesia tahun 2017 - 2019. Proporsi dewan komisaris independen dan kepemilikan institusional berpengaruh negatif tidak signifikan terhadap EPS pada perusahaan manufaktur yang tercatat pada Bursa Efek Indonesia tahun 2017 - 2019. Komite audit berpengaruh positif tidak signifikan terhadap EPS pada perusahaan manufaktur yang tercatat pada Bursa Efek Indonesia tahun 2017 - 2019. Mekanisme good corporate governance berpengaruh positif tidak signifikan terhadap Tobin's Q pada perusahaan manufaktur yang tercatat pada Bursan Efek Indonesia tahun 2017 - 2019.

4) Corporate social responsibility berpengaruh negatif tidak signifikan terhadap financial performance pada perusahaan manufaktur yang tercatat pada Bursa Efek Indonesia tahun 2017 - 2019.

5) Earnings management berpengaruh negatif tidak signifikan terhadap ROA pada perusahaan manufaktur yang tercatat pada Bursa Efek Indonesia tahun 2017 - 2019. Earnings management berpengaruh negatif signifikan terhadap tobin's Q pada perusahaan manufaktur yang tercatat pada Bursa Efek Indonesia tahun 2017 - 2019. Earnings management berpengaruh positif tidak signifikan terhadap EPS pada perusahaan manufaktur yang tercatat pada Bursa Efek Indonesia tahun 2017 - 2019.

6) Mekanisme good corporate governance berpengaruh positif terhadap ROA dan EPS dengan dimediasi oleh earnings management pada perusahaan manufaktur yang 
tercatat pada Bursa Efek Indonesia tahun 2017 - 2019. Mekanisme good corporate governance berpengaruh negatif terhadap tobin's Q dengan dimediasi oleh earnings management pada perusahaan manufaktur yang tercatat pada Bursa Efek Indonesia tahun $2017-2019$.

7) Corporate social responsibility berpengaruh positif terhadap financial performance dengan dimediasi oleh earnings management pada perusahaan manufaktur yang tercatat pada Bursa Efek Indonesia tahun 2017 - 2019.

\section{DAFTAR PUSTAKA}

IAI (2007), Financial Accounting Standards, Jakarta, Ikatan Akuntan Indonesia (in Bahasa).

Kurniati, S. (2019). Stock returns and financial performance as mediation variables in the influence of good corporate governance on corporate value. Corporate Governance: The International Journal of Business in Society.

Liu, H., \& Lee, H. A. (2019). The effect of corporate social responsibility on earnings management and tax avoidance in Chinese listed companies. International Journal of Accounting \& Information Management.

Mahrani, M., \& Soewarno, N. (2018). The effect of good corporate governance mechanism and corporate social responsibility on financial performance with earnings management as mediating variable. Asian Journal of Accounting Research.

Meutia, I. (2004). Pengaruh independensi auditor terhadap manajemen laba untuk KAP big 5 dan non big 5. The Indonesian Journal of Accounting Research, 7(3).

Tunggal, H. S. (2013). Internal Audit \& Corporate Governnace. Harvarindo.

Wibisono, Y. (2007). Membedah konsep \& aplikasi CSR: corporate social responsibility. Fascho Pub.. 